\title{
The effect of methyl jasmonate on selected physiological parameters of copper-treated Phaseolus coccineus plants
}

\author{
Agnieszka Hanaka • Waldemar Maksymiec • \\ Wiesław Bednarek
}

Received: 16 October 2014/ Accepted: 26 February 2015/Published online: 4 March 2015

(C) The Author(s) 2015. This article is published with open access at Springerlink.com

\begin{abstract}
Phaseolus coccineus plants in the early growth stage were preincubated with $10^{-5} \mathrm{M}$ methyl jasmonate (MJ) for 1 or $24 \mathrm{~h}$ and subsequently transferred to a Hoagland solution or treated with 50 or $100 \mu \mathrm{M}$ copper $\mathrm{Cu}$. After 6-day exposure to the metal, plant growth, relative water content, electrolyte leakage, the content of $\mathrm{Cu}$ and photosynthetic pigments, and chlorophyll fluorescence parameters were assayed. Generally, under $\mathrm{Cu}$ excess, $\mathrm{MJ}$ did not modulate growth parameters such as leaf area, root growth, shoot and root fresh weight, and the shoot/root fresh weight ratio. The content of chlorophyll $a, b$, and carotenoids increased with the increasing $\mathrm{Cu}$ content in the leaves. However, a correlation between the reduction of the leaf area and the lower content of the three photosynthetic pigments for $24-\mathrm{h} \mathrm{MJ}+100-\mu \mathrm{M} \mathrm{Cu}$ treatment compared with metal alone was noted. The decrease in the $\mathrm{Cu}$ concentration was MJ-dependent only after $1-\mathrm{h} \mathrm{MJ}+50-\mu \mathrm{M}$ $\mathrm{Cu}$ treatment in leaves and after $24-\mathrm{h} \mathrm{MJ}+100-\mu \mathrm{M} \mathrm{Cu}$ treatment in roots. Chlorophyll fluorescence was a weak indicator of the effect induced by $\mathrm{MJ}$ in $\mathrm{Cu}$ excess, and the most spectacular increase was observed for 1-h and 24-h $\mathrm{MJ}+50 \mu \mathrm{M} \mathrm{Cu}$ in the $\mathrm{LNU}$ and for $1-\mathrm{h} \mathrm{MJ}+50 \mu \mathrm{M} \mathrm{Cu}$ in the NPQ parameter. These results suggested a lack of a
\end{abstract}

Electronic supplementary material The online version of this article (doi:10.1007/s10725-015-0048-8) contains supplementary material, which is available to authorized users.

\footnotetext{
A. Hanaka $(\bowtie) \cdot$ W. Maksymiec

Department of Plant Physiology, M. Curie-Skłodowska

University, Akademicka 19, 20-033 Lublin, Poland

e-mail: agnieszka.hanaka@umcs.pl

W. Bednarek

Department of Agricultural and Environmental Chemistry,

University of Life Sciences in Lublin, Akademicka 15,

20-033 Lublin, Poland
}

clear pattern for $\mathrm{MJ}$ altering the $\mathrm{Cu}$ stress in the runner bean plants. The most important finding was that photosynthesis seemed to be quite resistant to $\mathrm{Cu}$ stress and slight modifications in chlorophyll fluorescence were accompanied by significant changes in growth parameters, photosynthetic pigment content, and metal content in the plant. The results obtained may have been strongly related to the plant growth stage, as the measured parameters transform greatly during plant growth and development.

Keywords Chlorophyll $a$ fluorescence $\cdot \mathrm{Cu}^{2+}$. Jasmonate - Photosynthetic pigments · Phytohormone . Runner bean

\section{Introduction}

Jasmonates, a collective name for jasmonic acid (JA) and its derivatives, such as a volatile methyl jasmonate (MJ), are widespread in the plant kingdom. They originate from oxidation of linolenic acid and are naturally appearing phytohormones. JA and MJ are precursors of the bioactive molecule in JA signaling represented by the isoleucine conjugated jasmonoyl derivative (Wasternack and Hause 2013). MJ triggers reprogramming of gene expression (Jung et al. 2010), which allows plant cells to deal with stresses (Wolucka et al. 2005). Moreover, genes encoding JA biosynthesis enzymes, OPDA-reductase, lipoxygenase, and allene oxide synthase, exhibited up-regulated expression under 100- $\mu \mathrm{M}$ MJ treatment (Jung et al. 2007).

Exogenously applied MJ inhibits or activates morphological, physiological, and biochemical changes in plants in a different manner depending on the plant growth stage and on the MJ application time and concentration. At a concentration of $100 \mu \mathrm{M}$ or higher $\mathrm{MJ}$ repressed germination 
and plant growth (Jubany-Marí et al. 2010; Kobayashi et al. 2010) and genes involved in photosynthesis, such as ribulose bisphosphate carboxylase/oxygenase (Rubisco), chlorophyll $a / b$-binding protein, light harvesting complex II, and early light-induced proteins, were down-regulated (Jung et al. 2007). At a concentration of $50 \mu \mathrm{M}$ or lower, MJ mostly, but not always (Noir et al. 2013), stimulated plant growth, lateral root initiation and growth, dry matter accumulation, biomass production, photosynthetic pigment levels, and elevation of the net photosynthetic rate (Tung et al. 1996; Mabood et al. 2006; Piotrowska et al. 2010; Wu et al. 2012). However, the role of MJ in protecting plants from various abiotic stresses has been controversial. For instance, $\mathrm{MJ}$ in rice improved resistance against chilling (Lee et al. 1996); however, application thereof caused growth reduction (Kim et al. 2009).

Among different stresses, heavy metal toxicity is currently a major abiotic factor that is turning a severe risk worldwide. Even short exposition to the excess of heavy metals, such as $\mathrm{Cu}$, gives visual and physiological changes in plants (Maksymiec and Krupa 2002, 2007), which suggests contribution of signaling pathways based on $\mathrm{MJ}$ (Maksymiec et al. 2005; Maksymiec 2007).

Photosynthetic pigments can be used with success as dependable indicators to evaluate the level of metal stress due to inactivation of photosynthesis, which is combined with loss of chlorophyll contents (Maksymiec and Baszyński 1996b; Cambrollé et al. 2013). Moreover, chlorophyll fluorescence has been employed in physiological and ecophysiological studies; since it is considered to be plant species-specific and is emitted only by fluorophores, such as chlorophyll $a(\mathrm{Chl} a)$, the fluorescence analysis is a useful tool for in vivo measurement of the stress level in plants (Maksymiec and Krupa 2002; Demmig-Adams et al. 2012).

To our knowledge, few studies have been carried out on MJ effects under heavy metal stress (Maksymiec and Krupa 2002; Keramat et al. 2010; Yan et al. 2013) and only single studies have been conducted on plants affected by MJ prior to $\mathrm{Cu}$ stress action (Maksymiec and Krupa 2002, 2007). The effect of excess $\mathrm{Cu}$ on $P$. coccineus, a model dicotyledonous plant, has been thoroughly examined by Maksymiec and Baszyński (1996a, b). Moreover, the literature confirms that plant reaction to $\mathrm{Cu}$ is the growth stage-dependent, but limited amount of research was conducted in the early growth stage (Maksymiec and Baszyński 1996b). Additionally, the way of MJ action through the octadecenoic pathway in $\mathrm{Cu}$ stress still needs clarification (Maksymiec and Krupa 2002). In the present work, we focused mainly on growth parameters (expressed as leaf area, root growth, plant biomass), $\mathrm{Cu}$ and photosynthetic pigment content, and photosynthetic apparatus activity of runner bean to evaluate the role of exogenously applied MJ on the physiology of the $\mathrm{Cu}$ stressed plant in its early growth stage and to examine the effects of shorter and longer MJ incubation under two $\mathrm{Cu}$ concentrations. $\mathrm{MJ}$ and $\mathrm{Cu}$ doses were selected on the basis of the results achieved in earlier experiments (Hristova and Popova 2002; Maksymiec and Krupa 2002).

\section{Materials and methods}

Plant material and growth conditions

Runner bean plants ( $P$. coccineus L. cv. Piękny Jaś) were germinated for 3 days and then cultivated hydroponically for 8 days in a Hoagland nutrient solution continuously aerated by air pumps. Hoagland's solution was changed after 2 days, shortly before supplementation with the metal. The plants were grown in a growth chamber in Maria Curie-Skłodowska University in Lublin, Poland, at $24 / 18{ }^{\circ} \mathrm{C}$ day/night temperature, relative humidity $60-70 \%$, and photosynthetic photon flux density of $120 \mu \mathrm{mol} \mathrm{m} \mathrm{m}^{-2} \mathrm{~s}^{-1}$ under a $16 \mathrm{~h}$ photoperiod. The plants were divided into nine groups: control plants-cultivated in the Hoagland nutrient solution only $(\mathrm{MJOCu})$, treated with $50(\mathrm{MJ} 0 \mathrm{Cu} 50)$ or $100 \mu \mathrm{M}$ (MJOCu100) copper as $\mathrm{CuSO}_{4} \times 5 \mathrm{H}_{2} \mathrm{O}$ (after 2 days of acclimation in hydroponic culture), preincubated with $10^{-5} \mathrm{M} \mathrm{MJ}$ for 1 or $24 \mathrm{~h}$ (after 2 days or 1 day of acclimation in hydroponic culture, respectively), and then transferred to the pure nutrient solution $(\mathrm{MJ} 1 \mathrm{Cu} 0$ or $\mathrm{MJ} 24 \mathrm{Cu} 0)$, or to the solution with addition of $50 \mu \mathrm{M} \mathrm{Cu}^{2+}(\mathrm{MJ} 1 \mathrm{Cu} 50$ or $\mathrm{MJ} 24 \mathrm{Cu} 50)$ or $100 \mu \mathrm{M} \mathrm{Cu}^{2+}$ (MJ1Cu100 or MJ24Cu100). After 6 days of metal treatment, the leaves and roots were examined or harvested for analysis.

\section{Determination of growth parameters}

Net root growth was calculated as the difference between the initial (shortly before the time of metal addition) and final (at the end of the experiment) lengths.

Measurements of the relative water content and electrolyte leakage

The relative water content (RWC) in shoots and roots was determined by measuring fresh weight (FW) and dry weight (DW) of shoots and roots, respectively, and calculated according to the equation: $\operatorname{RWC}(\%)=(\mathrm{FW}-\mathrm{DW}) /$ FW $\times 100$.

Leaf disks (0.2 g; $6 \mathrm{~mm}$ of diameter each) from fresh leaves of control and treated plants were washed with $40 \mathrm{~mL}$ of ultrapure water (MilliQ, Millipore, USA) for $3 \mathrm{~min}$ to remove surface-adhered electrolytes and dried with filter paper. The samples were placed in test tubes 
containing $10 \mathrm{~mL}$ of ultrapure water and gently shaken for $3 \mathrm{~h}$ at $25^{\circ} \mathrm{C}$, then conductivity (C1) was measured using an MPC227 meter (Mettler Toledo, Switzerland). Next, the samples were heated in a thermoblock at $95{ }^{\circ} \mathrm{C}$ for $20 \mathrm{~min}$, and the conductivity $(\mathrm{C} 2)$ was measured. Relative electrolyte leakage (REL) was defined as REL $(\%)=(\mathrm{C} 1 /$ C2) $\times 100$.

\section{Determination of the copper content}

The leaves and roots were rinsed in distilled water and dried at $105{ }^{\circ} \mathrm{C}$ to constant dry weight. Samples of $0.2-0.3 \mathrm{~g}$ DW were wet digested in the mixture of concentrated $\mathrm{HNO}_{3}+\mathrm{HClO}_{4}(4: 1, \mathrm{v} / \mathrm{v})$ using a Velp Scientica digester, DK20 (Milan, Italy). The $\mathrm{Cu}$ content was determined by atomic absorption spectrophotometry (Polarized Zeeman Z-8200, Hitachi, Japan).

Bioaccumulation (BAF) and translocation factors (TF) were defined as follows: the ratio of the metal concentration in the plant organ to that in the solution and the ratio of the metal concentration in leaves to that of roots, respectively. $\mathrm{TF}$ allows measuring the effectiveness of the plant in translocating the metal from roots to leaves.

Measurements of the photosynthetic pigment content

Chl $a$ and chlorophyll $b(\mathrm{Chl} b)$ and total carotenoids (Car) were extracted using $80 \%$ acetone and their concentrations were determined spectrophotometrically (UV-160A Shimadzu, Japan) according to Wellburn (1994).

\section{Measurements of the chlorophyll fluorescence}

Chlorophyll $a$ fluorescence was measured at $20{ }^{\circ} \mathrm{C}$ using a PAM 101 Chlorophyll Fluorometer (H. Waltz, Effeltrich, Germany) equipped with a PDA-100 system and Schott KL 1500 lamps. Prior to the measurements of fluorescence intensity, leaf sections were dark-adapted for at least $30 \mathrm{~min}$ in order to relax the reaction center. The minimal fluorescence level in the dark-adapted state $\left(\mathrm{F}_{0}\right)$ was measured using a photon fluence rate of $10 \mathrm{nmol} \mathrm{m}^{-2} \mathrm{~s}^{-1}$ at $1.6 \mathrm{kHz}$. The maximal fluorescence level at the darkadapted state $\left(\mathrm{F}_{\mathrm{m}}\right)$ was measured after applying a saturating light pulse of $8100 \mu \mathrm{mol} \mathrm{m} \mathrm{m}^{-2} \mathrm{~s}^{-1}$. Then, two other parameters were determined: the maximal fluorescence level at the light-adapted state $\left(\mathrm{F}_{\mathrm{m}}{ }^{\prime}\right)$ and the minimal fluorescence level in the light-adapted state $\left(\mathrm{F}_{0}{ }^{\prime}\right)$ after turning on the actinic light of $190 \mu \mathrm{mol} \mathrm{m}{ }^{-2} \mathrm{~s}^{-1}$ or applying a far-red light of $6 \mu \mathrm{mol} \mathrm{m} \mathrm{m}^{-2} \mathrm{~s}^{-1}$, respectively.

Using fluorescence parameters determined in both lightand dark-adapted states, the following parameters were calculated: maximum quantum efficiency of PSII photochemistry in the dark adapted state $\left(\mathrm{F}_{\mathrm{v}} / \mathrm{F}_{\mathrm{m}}\right)$, photochemical quenching of fluorescence (qP), non-photochemical quenching (NPQ), fraction of the absorbed light energy not used for photochemistry (LNU), and variable chlorophyll fluorescence decrease ratio/vitality index $\left(\mathrm{R}_{\mathrm{fd}}\right)$. The two latter parameters are calculated according to the following equations: $\mathrm{LNU}=1-\left(\mathrm{qP} \mathrm{F} \mathrm{F}_{\mathrm{v}}{ }^{\prime} \mathrm{F}_{\mathrm{m}}\right) /\left(\mathrm{F}_{\mathrm{m}}{ }^{\prime} \mathrm{F}_{\mathrm{v}}\right), \mathrm{R}_{\mathrm{fd}}=\left(\mathrm{F}_{\mathrm{m}}-\mathrm{F}_{\mathrm{s}}\right) / \mathrm{F}_{\mathrm{s}}$.

Statistical analysis

All analyses in this work were repeated at least four times with five replicates, except for the data of the $\mathrm{Cu}$ content which were obtained from three independent experiments with two replicates each, and presented as the mean values \pm SE. Statistical analyses were carried out using twoway ANOVA and Tukey's post hoc analysis for determination of the interaction significance at $p<0.05$. The results of the principal component analysis (PCA) were obtained from three independent replications. The data were analyzed using Statistica ver. 6 (StatSoft, Inc. 2004).

\section{Results}

Growth parameters

\section{Leaf area}

After MJ preincubation, $\mathrm{Cu}$ addition yielded a significantly smaller leaf area in all the experimental combinations without considerable differences between $\mathrm{MJ}+\mathrm{Cu}$ supplementation or $\mathrm{Cu}$ doses only (from 7.8 to $18.1 \%$ of the control) (Fig. 1a). Moreover, in MJ24Cu100 a significantly smaller leaf area compared with the metal alone was achieved. Plants preincubated with MJ for $24 \mathrm{~h}$ exhibited the biggest leaf area among all the plant groups tested (17.8\% higher than in the control) (Fig. 1a).

\section{Net root growth}

No influence of $\mathrm{MJ}$ on plants exposed to $\mathrm{Cu}$ was detected, but MJ alone strongly reduced the NGR parameter (Fig. 1b). A significant difference was detected between plants growing with and without $\mathrm{Cu}$ supplementation.

\section{Plant biomass}

MJ had no significant influence on $\mathrm{Cu}$ stress in the fresh weight of shoots and roots. The fresh weight of shoots was gradually lower; first for the $24 \mathrm{~h}$ MJ preincubated plants, then in the plants treated with $50 \mu \mathrm{M} \mathrm{Cu}$, and it was the lowest in the plants treated with $100 \mu \mathrm{M} \mathrm{Cu}$ (Fig. 1c). The highest fresh weight of roots was obtained after preincubation of plants with MJ and the lowest for all metal 

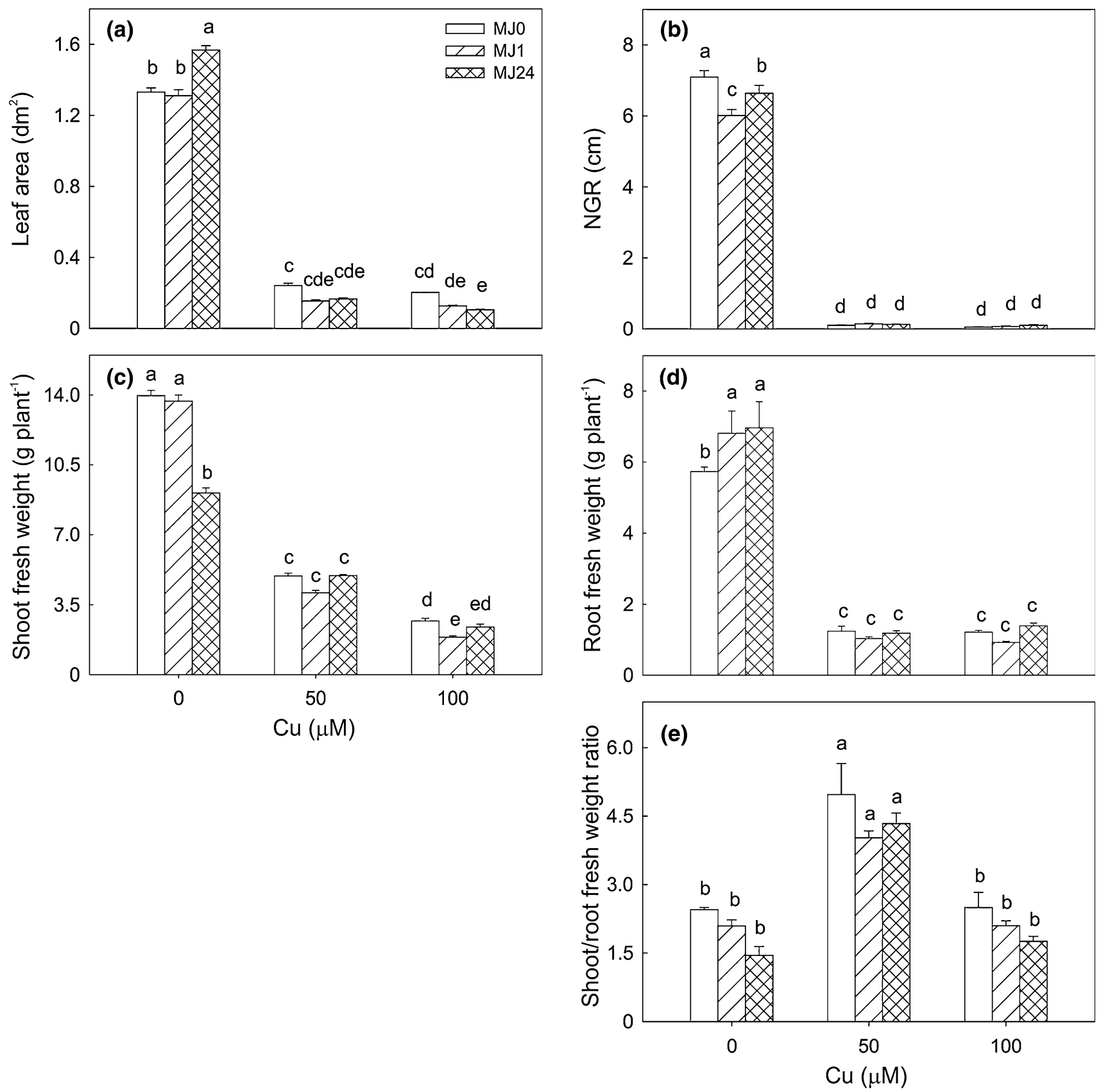

Fig. 1 Primary leaf area (a), relative root growth (b), fresh weight of shoots (c) and roots (d), and the shoot/root weight ratio (e) in runner bean plants. The control and copper-treated plants, after MJ pre-

treatments (Fig. 1d). The highest values of the shoot/root ratios were obtained only for the lower $\mathrm{Cu}$ doses without any difference in the other cases (Fig. 1e).

The reverse relationships between the leaf area and shoot fresh weight for the 24-h MJ incubation and between NGR and root fresh weight after 1-h and 24-h MJ action were detected. Moreover, the reverse relationships were observed between the leaf area and NGR, and shoot and root fresh weight for the 24-h MJ incubation.

exposure for $1 \mathrm{~h}$ (MJ1) or $24 \mathrm{~h}$ (MJ24), were analyzed 6 days after metal supplementation. The data represent the mean \pm SE $(n=20$, at least), the different letters indicated the interactions significant

Relative water content and electrolyte leakage

Preincubation with MJ did not modify RWC in the adverse $\mathrm{Cu}$ conditions in shoots or in roots. Generally, a lower RWC was found in the roots (from $85.2 \% \pm 0.91$ to $86.7 \% \pm 0.54$ and from $89.1 \% \pm 0.31$ to $89.9 \% \pm 0.51$ for the $\mathrm{Cu}$-treated and non-metal-treated plants, respectively) (data not shown) than in the leaves (from $88.9 \% \pm 0.91$ to $91.1 \% \pm 0.28$ and from $94.9 \% \pm 0.10$ 
to $95 \% \pm 0.14$ for the $\mathrm{Cu}$-treated and non-metal treated plants, respectively) (data not shown). In the leaves and roots, a significantly highest RWC was found in the non$\mathrm{Cu}$-treated plants (data not shown).

Addition of MJ for 1 or $24 \mathrm{~h}$ before application of $50 \mu \mathrm{M}$ $\mathrm{Cu}(9.2 \% \pm 0.18$ e and $9.6 \% \pm 0.17$ de, respectively $)$ significantly diminished REL induced by $50 \mu \mathrm{M} \mathrm{Cu}$ $(13.6 \% \pm 0.24 \mathrm{c})$, but for $100 \mu \mathrm{M} \mathrm{Cu}$ lower REL was obtained only after 24-h MJ incubation $(12.1 \% \pm 0.09 \mathrm{~cd})$ than after 1-h MJ incubation or $100 \mu \mathrm{M} \mathrm{Cu}$ alone $(23.9 \% \pm 0.13 \mathrm{a}$ and $16.9 \% \pm 0.14 \mathrm{~b}$, respectively) (data not shown). Moreover, MJ applied for $24 \mathrm{~h}$ gave significantly higher REL $(15.9 \% \pm 0.38 \mathrm{~b})$ than the 1-h MJ action or control $(11.8 \% \pm 0.21$ cde and $11.6 \% \pm 0.38$ cde, respectively) (data not shown).

\section{Copper content}

Overall, the tissue $\mathrm{Cu}$ content was greater in the roots than in the leaves (Fig. 2a, b). The level of the $\mathrm{Cu}$ content in leaves was correlated with $\mathrm{Cu}$ supplementation, but not with its concentration or MJ addition (Fig. 2a). The only difference was found between MJOCu50 and MJ1Cu50 being higher for metal supplementation alone. In the roots, a gradual increase in the $\mathrm{Cu}$ concentration was observed with its rising dose (Fig. 2b). The 24-h MJ preincubation lowered the $\mathrm{Cu}$ concentration in roots supplemented with $100 \mu \mathrm{M} \mathrm{Cu}$ in comparison with the metal alone. At $\mathrm{MJ} 1 \mathrm{Cu} 50$, the $\mathrm{Cu}$ passage from roots to leaves was reduced compared with the control, but such an effect was not seen at the higher metal doses; therefore, the observed effect of MJ was dependent on the $\mathrm{Cu}$ dose. $\mathrm{MJ}$ in combination with $50 \mu \mathrm{M} \mathrm{Cu}$ gave higher disparity between the leaves and roots (85-117-fold difference) than the metal alone (71fold difference), but this was reverse at the higher metal concentration (141-145 and 170-fold difference for the treatments with $\mathrm{MJ}+\mathrm{Cu}$ and $\mathrm{Cu}$ alone, respectively). Relatively small amounts of $\mathrm{Cu}$ were transported from the roots to leaves, especially when $100 \mu \mathrm{M} \mathrm{Cu}$ was added.

The BAF values were significantly higher in the roots than in the leaves. In the leaves, MJ action, to some extent, was more pronounced in plants under $50-\mu \mathrm{M}$ than $100-\mu \mathrm{M} \mathrm{Cu}$ stress, and the relation between the BAF values and the $\mathrm{Cu}$ content was as follows: MJ0Cu50 (3.52) $>$ MJ24Cu50 (2.94) $>\mathrm{MJ} 1 \mathrm{Cu} 50 \quad(2.63)>\mathrm{MJ} 1 \mathrm{Cu} 100 \quad(1.77)>\mathrm{MJ} 0 \mathrm{Cu}$ 100 (1.73) > MJ24Cu100 (1.53). In turn, the BAF values in the roots were mainly dependent on the length of the preincubation with $\mathrm{MJ}$ and were as follows: MJ1Cu50 $\begin{array}{lll}(307.9) & >\mathrm{MJ} 0 \mathrm{Cu} 100 & (295.2)>\mathrm{MJ} 1 \mathrm{Cu} 100 \quad(256.8)>\end{array}$ MJ24Cu50 (251.1) $>$ MJ0Cu50 (248.5) $>$ MJ24Cu100 (215.1). The sequence of TF values detected in the runner bean plants being mostly dependent on the length of MJ incubation in $50-\mu \mathrm{M} \mathrm{Cu}$ treated plants was as follows: MJ0Cu50
$(0.014)>\mathrm{MJ} 24 \mathrm{Cu} 50 \quad(0.012)>\mathrm{MJ} 1 \mathrm{Cu} 50 \quad(0.009)>$ MJ24Cu100 (0.007) $\geq$ MJ1Cu100 (0.007) $>$ MJ0Cu100 (0.006). The higher $\mathrm{Cu}$ concentration applied was accompanied by the lower TF.

\section{Photosynthetic pigments}

For the three photosynthetic pigments, $\mathrm{Chl} a, \mathrm{Chl} b$ and Car, the same pattern of statistical results was revealed. Regardless of the $\mathrm{MJ}$ preincubation, the higher the $\mathrm{Cu}$ dose, the higher the $\mathrm{Chl} a, \mathrm{Chl} b$, and Car contents were (Fig. 2c-e). Only the MJ preincubation for $24 \mathrm{~h}$ with the subsequent $100-\mu \mathrm{M} \mathrm{Cu}$ application decreased the concentration of all the three pigments, which was still significantly higher than for the control and MJ-treated plants. MJ did not alter the $\mathrm{Chl} a / \mathrm{chl} b$ ratio and $\mathrm{Chl}$ $(a+b) /$ car ratio in the $\mathrm{Cu}$-treated plants (Fig. 2f, g). In plants preincubated with $\mathrm{MJ}$ for $24 \mathrm{~h}$, the highest $\mathrm{Chl} a / \mathrm{chl} b$ ratio and, by contrast, the lowest $\mathrm{Chl}(a+b) / \mathrm{car}$ ratio of all treatments without $\mathrm{Cu}$ were detected (Fig. 2f, g). For all combinations with $50 \mu \mathrm{MCu}$, only the metal alone gave a lower $\mathrm{Chl}$ $a / \mathrm{chl} b$ ratio and MJ0Cu50 and MJ1Cu50 gave a lower Chl $(a+b) /$ car ratio than in the analogical experimental combinations without metal supplementation (Fig. 2f, g). Moreover, the higher $\mathrm{Cu}$ dose gave significantly lower $\mathrm{Chl} a / \mathrm{chl} b$ and $\mathrm{Chl}(a+b) /$ car ratios, compared with the control, except for MJ24Cu100 for the latter ratio (Fig. 2f, g).

\section{Chlorophyll fluorescence}

In the 50- $\mu \mathrm{M} \mathrm{Cu}$ treated plants, $\mathrm{MJ}$ did not change the $\mathrm{F}_{\mathrm{v}} / \mathrm{F}_{\mathrm{m}}$ value, but when $\mathrm{MJ}+\mathrm{Cu}$ was compared with $\mathrm{MJ}$ alone, it reached a similar level, simultaneously higher than for the $50-\mu \mathrm{M} \mathrm{Cu}$ treated plants (Fig. 3a). Furthermore, the values of $\mathrm{F}_{\mathrm{v}} / \mathrm{F}_{\mathrm{m}}$ were statistically lower for MJ0Cu50 and all the treatments with $100 \mu \mathrm{M} \mathrm{Cu}$ compared with the control. After MJ supplementation, the LNU value rose significantly under $50-\mu \mathrm{M} \mathrm{Cu}$ application, simultaneously not having an influence on $100-\mu \mathrm{M} \mathrm{Cu}$ treatment (Fig. 3b). Generally, the LNU values were significantly higher for all $\mathrm{MJ}+\mathrm{Cu}$ treatments and for MJOCu100 compared with the control (Fig. 3b). MJ did not exert any effect on the qP parameter in plants exposed to $\mathrm{Cu}$, but $\mathrm{MJ} 1 \mathrm{Cu} 100$ exhibited the lowest value when compared with MJ alone (Fig. 3c). MJ caused elevation of the NPQ value under $50-\mu \mathrm{M} \mathrm{Cu}$ excess compared with the metal alone, but had no effect on $100-\mu \mathrm{M} \mathrm{Cu}$ addition (Fig. 3d). The highest NPQ values were found after metal treatment, except for MJ0Cu50 and MJ1Cu100. MJ did not cause any effect on the $\mathrm{R}_{\mathrm{fd}}$ values under $\mathrm{Cu}$ treatment (data not shown). The only significant difference in this parameter was found between the control $\left(\mathrm{R}_{\mathrm{fd}}=3.33\right.$ - the highest value) and $100 \mu \mathrm{M} \mathrm{Cu}\left(\mathrm{R}_{\mathrm{fd}}=3.14\right.$-the lowest value).

Two principal factors of PCA explained $60.1 \%$ of the variation, with $\mathrm{PC} 1$ and $\mathrm{PC} 2$ variability of 36.8 and $23.3 \%$, 

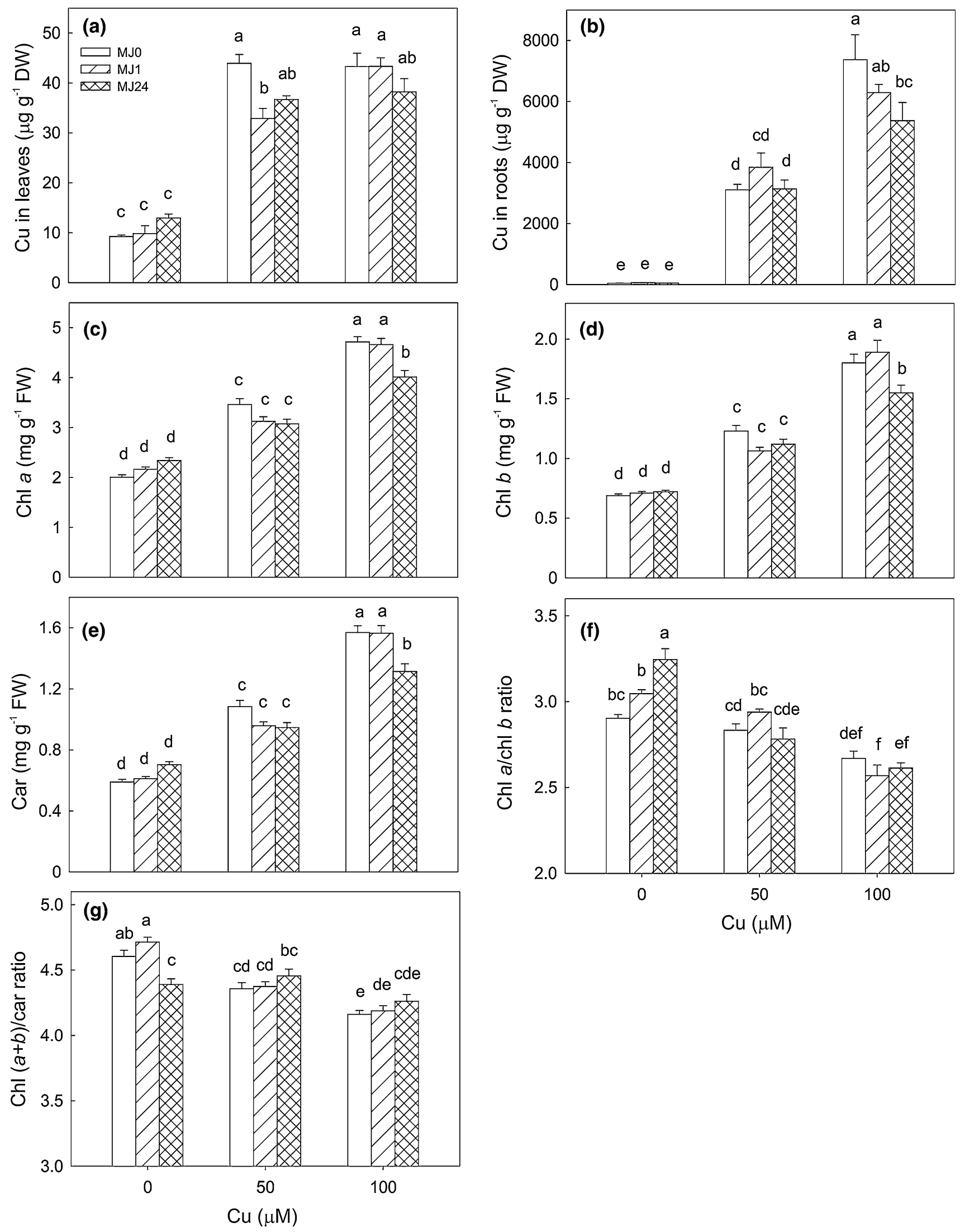
4Fig. 2 Content of copper in leaves (a), roots (b), content of chlorophyll $a$ (c), chlorophyll $b$ (d), carotenoids (e), ratio of chlorophyll $a$ /chlorophyll $b$ (f), chlorophyll $(a+b) /$ carotenoids (g) in the leaves of runner bean plants. The control and coppertreated plants, after MJ pre-exposure for $1 \mathrm{~h}$ (MJ1) or $24 \mathrm{~h}$ (MJ24), were analyzed 6 days after metal supplementation. The data represent the mean $\pm \operatorname{SE}(\mathrm{n}=6$ for the $\mathrm{Cu}$ content and $\mathrm{n}=20$, at least, for the pigment content), the different letters indicate significant interactions

respectively (Supplementary Fig. 1). A majority of samples had negative PC1 scores and the distribution of the samples along the PC2 axes was less clear. PC1 was positively correlated with LNU and NPQ, and negatively with $\mathrm{qP}, \mathrm{R}_{\mathrm{fd}}$ and $\mathrm{F}_{\mathrm{v}} / \mathrm{F}_{\mathrm{m}}$. The strongest negative correlation of PC2 was found with NPQ. MJ was not a considerably separating agent, but all data concerning $100 \mu \mathrm{M} \mathrm{Cu}$ were well separated. Significantly worse separated data concerned the treatments with $50 \mu \mathrm{M} \mathrm{Cu}$ and without the metal.

\section{Discussion}

Our research proved that MJ was a potent molecule in changing growth parameters mostly in an incubation time-
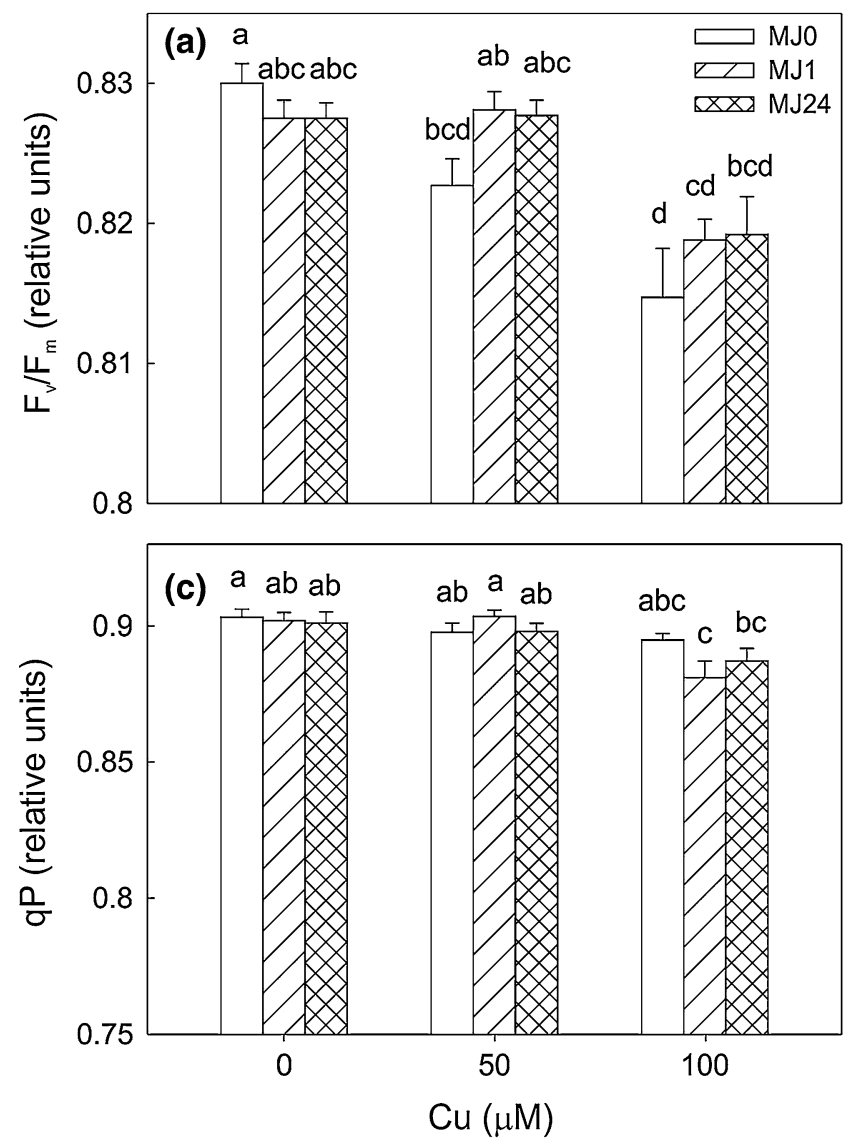

Fig. 3 Chlorophyll fluorescence parameters: $F_{v} / F_{m}(a), L N U(b), q P$ (c), NPQ (d) in the leaves of runner bean plants. The control and copper-treated plants, after MJ pre-exposure for $1 \mathrm{~h}(\mathrm{MJ} 1)$ or $24 \mathrm{~h}$ dependent manner. It is known that the leaf area and the number of cells are negatively correlated with the cell density (Kobayashi et al. 2010); hence, the greatest leaf area after the 24-h exposure to MJ may have been caused by the elevated number of cells. However, our results concerning the MJ influence on leaf area were opposed to these reported by Kobayashi et al. (2010) mainly because of the prominent differences in the MJ concentration. Furthermore, MJ synthesis takes place mainly in leaves; therefore, only leaves, but not the whole shoots, could be particularly sensitive to exogenous MJ. This statement is in agreement with our results - the highest leaf area after the $24 \mathrm{~h}$ MJ preincubation was correlated with lower shoot fresh weight, probably dependent on lower cell density.

Moreover, since MJ was applied directly to the nutrient solution where roots were immersed, the MJ signal could arrive straight at the root growth zone, where it was sensed. Next, it led to the reduction of cell growth (Schmidt et al. 2010) and inhibited cell proliferation and elongation (Noir et al. 2013). Additionally, MJ can directly or indirectly modulate the influence of auxin on root growth and development (Wasternack and Hause 2013). Consequently,
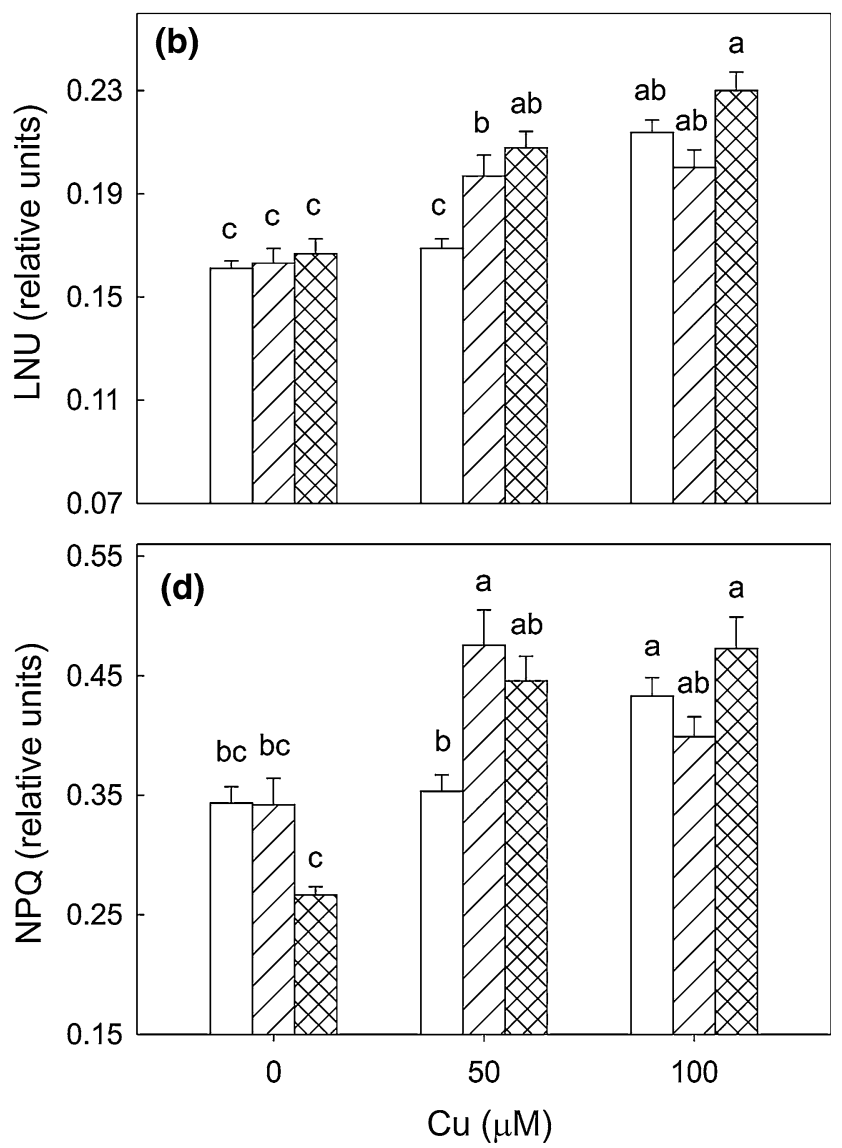

(MJ24), were analyzed 6 days after metal supplementation. The data represent the mean $\pm \mathrm{SE}(\mathrm{n}=20$, at least $)$, the different letters indicate significant interactions 
the cell size and number were reduced in our experiment resulting in decreased NGR, which could stimulate higher root density and, hence, increased root fresh weight.

For the 24-h MJ incubation, a reverse relationship between the leaf area and NGR and shoot and root fresh weight was observed, which revealed different susceptibility of shoots and roots to the MJ exposure. Regardless of its systemic distribution along the phloem, MJ is differently accumulated in various plant organs (Schmidt et al. 2010) and can provide better protection to leaves than to roots, which was evidenced by the significant decrease in NGR.

Despite the MJ stimulation of the leaf area and root fresh weight, in our research MJ did not serve a protective role in the case of the examined growth parameters in $\mathrm{Cu}$ stress. Other results demonstrated that at $10 \mu \mathrm{M}$ or a lower concentration, MJ protected plants growth from the negative influence of $\mathrm{Cu}$ and $\mathrm{Cd}$, but had no positive effect at a higher concentration (Maksymiec and Krupa 2002; Yan et al. 2013). Besides, the depressed $\mathrm{Cu}$ action on the leaf area is stronger than the protective role of $24-\mathrm{h}$ MJ preincubation. Therefore, the combined influence of $\mathrm{MJ}$ and $\mathrm{Cu}$ may result in an inhibitory effect of $\mathrm{Cu}$ not sustained by the too weak protective role of MJ. It seems that the results obtained could be dependent on the MJ incubation time and its concentration, plant species, and the strength of the stress agent. Moreover, our results demonstrated that MJ could not play an effective role of a protective barrier for $\mathrm{Cu}$ passage from roots to leaves.

In our experiment, runner bean seedlings exposed to $\mathrm{Cu}$ exhibited visible morphological changes, such as a significant decrease in the leaf area caused by decreasing cell wall elasticity (Maksymiec 2007), root length, and plant height, compared with the control plants. Moreover, the growth reduction was more pronounced in roots than in leaves at the lower $\mathrm{Cu}$ dose, which was reflected by considerably reduced values of shoot fresh weight and elevated values of the shoot/root fresh weight ratio. This observation is consistent with the experiment with $75 \mu \mathrm{M} \mathrm{Cu}$ conducted by Gajewska and Skłodowska (2010).

Furthermore, $\mathrm{Cu}$ exhibited low translocation to the above-ground parts of the plant, since it was mostly retained by the roots (Gajewska and Skłodowska 2010; Cambrollé et al. 2013), which was confirmed by the BAF and TF values (higher and lower than 1, respectively) calculated in the present research. The difference in the distribution of the uptaken metal between leaves and roots was caused by efficiently working mechanisms of blocking $\mathrm{Cu}$ translocation (plant excluders) and the fact that the growth inhibition was organ-dependent (Gajewska and Skłodowska 2010) and, in our experiment, it was more considerable in roots than in leaves. It is known that the translocation barrier works efficiently in some range of the metal dose; the tested $\mathrm{Cu}$ doses fit in this range and the above-ground part of the plant is protected from toxicity and destruction.

Our experiments showed that $\mathrm{MJ}$ was not a protector of the dehydration process under metal stress. Moreover, similarly to the results reported by other scientists $(\mathrm{Wu}$ et al. 2012; Mahmood et al. 2012), in the present study RWC showed no significant difference between the control and the $10 \mu \mathrm{M}$ MJ-treated plants, suggesting that the MJ treatment did not induce osmotic stress (Wu et al. 2012). On the other hand, excess of $\mathrm{Cu}$ is known to decrease RWC (Marschner 1995), and in our research a significantly lower RWC was detected after $\mathrm{Cu}$ supplementation.

We affirmed quite successfully maintenance of membrane stability by $\mathrm{MJ}$ in $\mathrm{Cu}$ stress conditions, although the higher the $\mathrm{Cu}$ concentration, the higher the REL. Furthermore, the level of permeability of leaf cellular membranes presented as REL was elevated under the 24-h MJ incubation, compared to the control, which is in accordance with other papers (Hristova and Popova 2002).

In our experiment, a less significant increase in the $\mathrm{Chl}$ content was detected for MJ24Cu100, but this could be explained as a possible effect of $\mathrm{Fe}$ and $\mathrm{Mg}$ deficiency and chlorophyllase activity stimulation by $\mathrm{MJ}$, but not by $\mathrm{Cu}$, which was confirmed by the increased levels of $\mathrm{Fe}^{3+}$ and $\mathrm{Mg}^{2+}$ after $100-\mu \mathrm{M} \mathrm{Cu}$ treatment (Martínez-Peñalver et al. 2012). Furthermore, the responses of accumulation of pigments, amino acids, and mineral nutrients were dependent on both MJ and metal concentration (Kováčik et al. 2011). The increase in the Chl $a / b$ ratio in leaves incubated for $24 \mathrm{~h}$ with $\mathrm{MJ}$ and the decrease in the $\mathrm{Chl}(a+b) /$ car ratio could be explained by a greater inhibitory effect on $\mathrm{Chl} b$ than $\mathrm{Chl}$ $a$ and induction of the senescence process after the longer MJ incubation, respectively. In general, photosynthetic pigments either decrease significantly after exposure to $\mathrm{Cu}$ (Maksymiec and Baszyński 1996b) or no effect is observed (Burzyński and Żurek 2007); however, we indicated that $\mathrm{Cu}$ increased $\mathrm{Chl}$ accumulation, which is in agreement with the results obtained at $80-\mu \mathrm{M} \mathrm{Cu}$ supplementation (Maksymiec and Baszyński 1996b) and 100- $\mu \mathrm{M} \mathrm{Cu}$ treatment (Fatima et al. 2011). In our research, MJ without metal supplementation did not alter the pigment content, although JA treatment can result not only in Chl reduction as a consequence of induction of the chlorophyllase gene (Tsuchiya et al. 1999), but also in Rubisco subunit reduction (Rakwal and Komatsu 2000).

Measurements of chlorophyll fluorescence provide valuable information about the efficiency of photochemical processes taking place inside the leaf. MJ did not exert any effect on $\mathrm{Cu}$ exposed plants in the $\mathrm{F}_{\mathrm{v}} / \mathrm{F}_{\mathrm{m}}$ ratio. The unchanged $\mathrm{F}_{\mathrm{v}} / \mathrm{F}_{\mathrm{m}}$ ratio in our experiments with $\mathrm{MJ} 1 \mathrm{Cu} 50$, MJ24Cu50 and MJ supplementation is in agreement with 
the results obtained in the initial growth stage in other research papers (Krupa et al. 1993; Maksymiec and Baszyński 1996a; Ananieva et al. 2007; Fedina et al. 2009) and suggests that the maximal photochemical yield of PSII was insensitive to $\mathrm{MJ}+50 \mu \mathrm{M} \mathrm{Cu}$ and to $\mathrm{MJ}$ alone. Besides, the level of $F_{v} / F_{m}$ ratio could be strongly dependent on the length of the MJ treatment (Jung 2004). In our experiment, the decrease in the $\mathrm{F}_{\mathrm{v}} / \mathrm{F}_{\mathrm{m}}$ for $\mathrm{MJ} 1 \mathrm{Cu} 100,50 \mu \mathrm{M} \mathrm{Cu}$ and $100 \mu \mathrm{M} \mathrm{Cu}$ could indicate damage to chloroplasts, especially thylakoid membranes (Yamane et al. 2003), induction of photoinhibition processes (Maxwell and Johnson 2000), or reversible inactivation rather than photodamage of PSII (Demmig-Adams et al. 2012).

The decline in $\mathrm{F}_{\mathrm{v}} / \mathrm{F}_{\mathrm{m}}$ may have also been correlated with the increase in NPQ caused by the conversion of violaxanthin to zeaxanthin (Jahns and Holzwarth 2012). A significant role in the development of NPQ is played by the PsbS subunit of PSII, the xanthophyll cycle, and a decrease in $\mathrm{pH}$, which operates as a signal for enhancement of NPQ (Jahns and Holzwarth 2012). In the present study, MJ alone did not alter the NPQ value, which agrees well with other findings (Jung 2004), but alleviated NPQ only in one case under $\mathrm{Cu}$ stress, i.e. MJ1Cu50. An increase in the NPQ parameter, as evidence of protection against photodamage, was observed for most treatments concerning the presence of the metal. Similarly to the research of Jung (2004) and Burzyński and Żurek (2007), we have not detected any significant change in the $\mathrm{qP}$ value, also in the $\mathrm{MJ}$ influence under the $\mathrm{Cu}$ treatment; therefore, the utilization of excitation energy to drive the photosynthetic electron transport was not a stress diversifying parameter in our research.

In our experimental conditions, $\mathrm{MJ}$ in the $50-\mu \mathrm{M} \mathrm{Cu}$ environment caused a rise in LNU, similarly to the most metal-treated plants when compared to the control. This could be interpreted as lower efficiency in utilization of the energy absorbed by the antenna complexes in photochemical processes of photosynthesis. Most $R_{\mathrm{fd}}$ values were similar to the control, being insensitive to the $\mathrm{MJ}$ and metal doses, except for the highest metal content, which reassured us that the photosynthetic apparatus and Calvin cycle worked correctly, even where simultaneous reduction of fresh weight of shoots, leaf area, and water content was observed. Our results are in agreement with other findings (Maksymiec and Baszyński 1996b).

It is well known that fluorescence parameters change severely during the plant growth and development and can differ significantly in the intensive, intermediate, and final growth stages (Maksymiec and Baszyński 1996a). The photosynthesis in the leaves exhibited age-dependent susceptibility to $\mathrm{Cu}$, i.e. young leaves were less sensitive to $\mathrm{Cu}$ than mature ones (Vinit-Dunand et al. 2002). Furthermore, the level of JA was also age-dependent, i.e. higher for younger than older leaves (Maksymiec et al. 2005), which suggests that JA may be involved in the cellular responses at the early stage of metal stress (Yan et al. 2013), and this may be the cause of the lower susceptibility to MJ detected in the early growth stage of runner bean plants. Besides, Maksymiec and Krupa (2002) reported an MJ dose-dependent influence on chlorophyll fluorescence parameters measured under $\mathrm{Cu}$ or $\mathrm{Cd}$ stress; MJ only up to $10 \mu \mathrm{M}$ provided protection and lost its positive effect at higher concentrations. Moreover, membrane stability measured as REL seemed to be fundamental for the maintenance of photosynthetic functions (Hristova and Popova 2002).

Despite the considerable and evident changes in the growth parameters accompanying the $\mathrm{MJ}$ and $\mathrm{Cu}$ supplementation, the photosynthetic apparatus remained partially untouched in our experimental conditions, which was in agreement with the literature data (Maksymiec and Baszyński 1996a, b). Moreover, the good condition of chloroplasts (membranes and granal structures) and the $\mathrm{Cu}$ supplementation-induced higher $\mathrm{Chl}$ content also detected by other scientists (Maksymiec and Baszyński 1996b; Fatima et al. 2011) could be the explanation for the not severely affected chlorophyll fluorescence parameters.

\section{Conclusions}

In conclusion, MJ did not demonstrate an obvious way of action in altering $\mathrm{Cu}$ stress in the early growth stage of $P$. coccineus plants. The growth parameters examined were mostly insensitive to $\mathrm{MJ}$ application under $\mathrm{Cu}$ treatment, but significantly higher growth parameters were reported in the control and MJ-treated plants. In the case of the MJ24Cu100 treatment, reduction of the leaf area and a lower content of three photosynthetic pigments compared with the metal alone were found. However, the 24-h MJ preincubation alone increased the leaf area and reduced the fresh weight of shoots, which corresponded with the elevated $\mathrm{Chl} a / \mathrm{chl}$ $b$ ratio and the decreased $\mathrm{Chl}(a+b) / \mathrm{car}$ ratio. Moreover, the increase in the $\mathrm{Cu}$ content corresponded with an increase in the $\mathrm{Chl} a, \mathrm{Chl} b$, and Car concentrations. Reduction of the $\mathrm{Cu}$ concentration was barely MJ-dependent (only after MJ1Cu50 treatment in leaves and after MJ24Cu100 treatment in roots). From all the parameters measured in this study, chlorophyll fluorescence was not a strong indicator of the effects caused by $\mathrm{MJ}, \mathrm{Cu}$, or the combination of both, but the most pronounced rise was found in LNU for MJ1Cu50, MJ24Cu50 and NPQ for MJ1Cu50. The PCA of the fluorescence parameters proved no MJ-dependent separation, but quite considerable separation for all treatments with $100 \mu \mathrm{M} \mathrm{Cu}$. The results suggested a lack of an unequivocal pattern for the $\mathrm{MJ}$ role in modification of the $\mathrm{Cu}$ stress in the 
runner bean plants. In summary, from the physiological point of view, the future research should inevitably be expanded to include enzymatic and non-enzymatic antioxidants for holistic interpretation of the results, explanation of possible interactions between $\mathrm{MJ}$ and $\mathrm{Cu}$, and elucidation of the mechanism of the MJ action in metal stress.

Acknowledgments The authors are grateful to Ewelina Nowak for technical assistance.

Conflict of interest The authors declare that they have no conflict of interest.

Open Access This article is distributed under the terms of the Creative Commons Attribution License which permits any use, distribution, and reproduction in any medium, provided the original author(s) and the source are credited.

\section{References}

Ananieva K, Ananiev ED, Mishev K, Georgieva K, Malbeck J, Kamínek M, Van Staden J (2007) Methyl jasmonate is a more effective senescence-promoting factor in Cucurbita pepo (zucchini) cotyledons when compared with darkness at the early stage of senescence. J Plant Physiol 164:1179-1187

Burzyński M, Żurek A (2007) Effects of copper and cadmium on photosynthesis in cucumber cotyledons. Photosynthetica 45:239-244

Cambrollé J, García JL, Ocete R, Figueroa ME, Cantos M (2013) Growth and photosynthetic responses to copper in wild grapevine. Chemosphere 93:294-301

Demmig-Adams B, Cohu CM, Muller O, Adams WWIII (2012) Modulation of photosynthetic energy conversion efficiency in nature: from seconds to seasons. Photosynth Res 113:75-88

Fatima N, Ahmad N, Anis M (2011) Enhanced in vitro regeneration and change in photosynthetic pigments, biomass and proline content in Withania somnifera L. (Dunal) induced by copper and zinc ions. Plant Physiol Biochem 49:1465-1471

Fedina I, Nedeva D, Georgieva K, Velitchkova M (2009) Methyl jasmonate counteract UV-B stress in barley seedlings. J Agronomy Crop Sci 195:204-212

Gajewska E, Skłodowska M (2010) Differential effect of equal copper, cadmium and nickel concentration on biochemical reactions in wheat seedlings. Ecotoxicol Environ Saf 73:996-1003

Hristova VA, Popova LP (2002) Treatment with methyl jasmonate alleviates the effects of paraquat on photosynthesis in barley plants. Photosynthetica 40:567-574

Jahns P, Holzwarth AR (2012) The role of the xanthophyll cycle and of lutein in photoprotection of photosystem II. Biochim Biophys Acta 1817:182-193

Jubany-Marí T, Prinsen E, Munné-Bosch S, Alegre L (2010) The timing of methyl jasmonate, hydrogen peroxide and ascorbate accumulation during water deficit and subsequent recovery in the Mediterranean shrub Cistus albidus L. Environ Exp Bot 69:47-55

Jung S (2004) Effect of chlorophyll reduction in Arabidopsis thaliana by methyl jasmonate or norflurazon on antioxidant systems. Plant Physiol Biochem 42:225-231

Jung C, Lyou SH, Yeu SY, Kim MA, Rhee S, Kim M, Lee JS, Choi YD, Cheong J-J (2007) Microarray-based screening of jasmonate-responsive genes in Arabidopsis thaliana. Plant Cell Rep 26:1053-1063

Jung C, Shim JS, Seo JS, Lee HY, Kim CH, Choi YD, Cheong J-J (2010) Non-specific phytohormonal induction of AtMYB44 and suppression of jasmonate-responsive gene activation in Arabidopsis thaliana. Mol Cells 29:71-76

Keramat B, Kalantari KM, Arvin MJ (2010) Effects of methyl jasmonate treatment on alleviation of cadmium damages in soybean. J Plant Nutr 33:1016-1025

Kim EH, Kim YS, Park S-H, Koo YJ, Choi YD, Chung Y-Y, Lee I-J, Kim J-K (2009) Methyl jasmonate reduces grain yield by mediating stress signals to alter spikelet development in rice. Plant Physiol 149:1751-1760

Kobayashi H, Yanaka M, Ikeda TM (2010) Exogenous methyl jasmonate alters trichome density on leaf surfaces of Rhodes grass (Chloris gayana Kunth). J Plant Growth Regul 29:506-511

Kováčik J, Klejdus B, Štork F, Hedbavny J, Bačkor M (2011) Comparison of methyl jasmonate and cadmium effect on selected physiological parameters in Scenedesmus quadricauda (chlorophyta, chlorophyceae). J Phycol 47:1044-1049

Krupa Z, Öquist G, Huner NPA (1993) The effects of cadmium on photosynthesis of Phaseolus vulgaris-a fluorescence analysis. Physiol Plant 88:626-630

Lee T-M, Lur H-S, Lin Y-H, Chu C (1996) Physiological and biochemical changes related to methyl jasmonate-induced chilling tolerance of rice (Oryza sativa L.) seedlings. Plant Cell Environ 19:65-74

Mabood F, Zhou X, Lee K-D, Smith DL (2006) Methyl jasmonate, alone or in combination with genistein, and Bradyrhizobium japonicum increases soybean (Glycine $\max \mathrm{L}$.) plant dry matter production and grain yield under short season conditions. Field Crop Res 95:412-419

Mahmood M, Bidabadi SS, Ghobadi C, Gray DJ (2012) Effect of methyl jasmonate treatments on alleviation of polyethylene glycol-mediated water stress in banana (Musa acuminata cv. "Berangan", AAA) shoot tip cultures. Plant Growth Regul 68:161-169

Maksymiec W (2007) Signaling responses in plants to heavy metal stress. Acta Physiol Plant 29:177-187

Maksymiec W, Baszyński T (1996a) Chlorophyll fluorescence in primary leaves of excess $\mathrm{Cu}$-treated runner bean plants depends on their growth stages and the duration of $\mathrm{Cu}$-action. J Plant Physiol 149:196-200

Maksymiec W, Baszyński T (1996b) Different susceptibility of runner bean plants to excess copper as a function of the growth stages of primary leaves. J Plant Physiol 149:217-221

Maksymiec W, Krupa Z (2002) Jasmonic acid and heavy metals in Arabidopsis plants-a similar physiological response to both stressors? J Plant Physiol 159:509-515

Maksymiec W, Krupa Z (2007) Effects of methyl jasmonate and excess copper on root and leaf growth. Biol Plant 51:322-326

Maksymiec W, Wianowska D, Dawidowicz AL, Radkiewicz S, Mardarowicz M, Krupa Z (2005) The level of jasmonic acid in Arabidopsis thaliana and Phaseolus coccineus plants under heavy metal stress. J Plant Physiol 162:1338-1346

Marschner H (1995) Mineral nutrition of higher plants, 2nd edn. Academic Press, London

Martínez-Peñalver A, Graña E, Reigosa MJ, Sánchez-Moreiras AM (2012) The early response of Arabidopsis thaliana to cadmiumand copper-induced stress. Environ Exp Bot 78:1-9

Maxwell K, Johnson GN (2000) Chlorophyll fluorescence-a practical guide. J Exp Bot 51:659-668

Noir S, Bömer M, Takahashi N, Ishida T, Tsui T-L, Balbi V, Shanahan H, Sugimoto K, Devoto A (2013) Jasmonate controls leaf growth by repressing cell proliferation and the onset of endoreduplication while maintaining a potential stand-by mode. Plant Physiol 161:1930-1951

Piotrowska A, Bajguz A, Czerpak R, Kot K (2010) Changes in the growth, chemical composition, and antioxidant activity in the 
aquatic plant Wolffia arrhiza (L.) Wimm. (Lemnaceae) exposed to jasmonic acid. J Plant Growth Regul 29:53-62

Rakwal R, Komatsu S (2000) Role of jasmonate in the rice (Oryza sativa L.) self-defense mechanism using proteome analysis. Electrophoresis 21:2492-2500

Schmidt L, Hummel GM, Schöttner M, Schurr U, Walter A (2010) Jasmonic acid does not mediate root growth response to wounding in Arabidopsis thaliana. Plant Cell Environ 33:104-116

Tsuchiya T, Ohta H, Okawa K, Iwamatsu A, Shimada H, Masuda T, Takamiya K (1999) Cloning of chlorophyllase, the key enzyme in chlorophyll degradation: finding of a lipase motif and the induction by methyl jasmonate. Proc Natl Acad Sci USA 96:15362-15367

Tung P, Hooker TS, Tampe PA, Reid DM, Thorpe TA (1996) Jasmonic acid: effects on growth and development of isolated tomato roots cultured in vitro. Int J Plant Sci 157:713-721

Vinit-Dunand F, Epron D, Alaoui-Sossé B, Badot P-M (2002) Effects of copper on growth and on photosynthesis of mature and expanding leaves in cucumber plants. Plant Sci 163:53-58

Wasternack C, Hause B (2013) Jasmonates: biosynthesis, perception, signal transduction and action in plant stress response, growth and development. An update to the 2007 review in Annals of Botany. Ann Bot 111:1021-1058

Wellburn AR (1994) The spectral determination of chlorophylls $a$ and $b$, as well as total carotenoids, using various solvents with spectrophotometers of different resolution. J Plant Physiol 144:307-313

Wolucka BA, Goossens A, Inzé D (2005) Methyl jasmonate stimulates the de novo biosynthesis of vitamin $\mathrm{C}$ in plant cell suspensions. J Exp Bot 56:2527-2538

Wu H, Wu X, Li Z, Duan L, Zhang M (2012) Physiological evaluation of drought stress tolerance and recovery in cauliflower (Brassica oleracea L.) seedlings treated with methyl jasmonate and coronatine. J Plant Growth Regul 31:113-123

Yamane K, Kawasaki M, Taniguchi M, Miyake H (2003) Differential effect of $\mathrm{NaCl}$ and polyethylene glycol on the ultrastructure of chloroplasts in rice seedlings. J Plant Physiol 160:573-575

Yan Z, Chen J, Li X (2013) Methyl jasmonates modulator of Cd toxicity in Capsicum frutescens var. fasciculatum seedlings. Ecotoxicol Environ Saf 98:203-209 